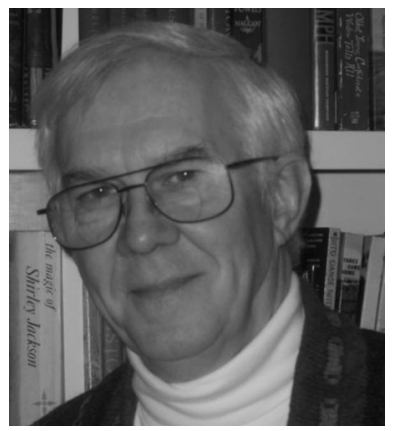

\section{Grooving on Technology}

Despite the enormous gusher of information that issues forth from the Internet, I choose to get my sense of the world in an old-fashioned form, print. That doesn't mean that I ignore other sources. I read our daily paper, the Atlanta Journal-Constitution, and selections from the New York Times and Washington Post, whose summaries appear in my e-mail inbox every morning. Some of this reading takes place while we listen to "Morning Edition" and "All Things Considered" from National Public Radio. Because the coverage by NPR is so extensive, we tape "NBC Nightly News" and watch it when it's convenient, to get a feel for what is being emphasized in the mainstream media. My wife and I refer to it as our "unreality check." (The choice of NBC comes from my childhood when I listened to Morgan Beatty. This was followed by John Cameron Swazye and others right up to the present day with Tom Brokaw. Changing networks for me would be like changing my chromosomes. I don't believe NBC is any better than others, it simply is what I'm used to.)

But once I get beyond the news of the day, I return to print. For diversion, I like good storytellers. So Tom Clancy, J. K. Rowling, Tracy Chevalier, and, of course, Patrick O'Brien's Aubrey and Maturin series provide great pleasure. But if there is any one field I enjoy reading about, it is the technology that shapes our world. I have already commented on Dava Sobel's Longitude, which describes George Harrison's work on the nautical chronometer ("The First Modern Engineer," March 1999). There are others, such as Tuxedo Park by Jennet Conant (Simon \& Schuster, 2002), which gave me an appreciation for the resourcefulness and ingenuity for the group of engineers at the Massachusetts Institute of Technology (MIT) that developed radar during World War II.

But technology changes rapidly and books can take years to get published. (My fellow authors on our SPIE diffractive optics text will testify to that. We started working on the manuscript in 1998 and it was finally published earlier this year.) So where do I go to appreciate and understand our technologies? For instant updates, I have the Web and its latest wrinkle, RSS feeds. But I find that with the exception of keeping up with Macintosh news, most technology information, Slashdot.com, for example, is so quantized, that one needs a sufficient accumulation of these items to make any sense of where technology is going.

Although some of its editorial features can be a bit loopy, I read Wired (http://www.wired.com) to provide glimpses into the future with the help of some good writers. It covers topics such as cloning, search engines, cinematic special effects and animation, robotics, warfare simulations, and, silly as it may seem, invisibility. Certainly the entertainment value may outweigh the information content, but Wired expands my horizon for technology.

Projecting the future is a dicey proposition in any case; a magazine that is considerably more grounded in the present is Technology Review (http:// www.technologyreview.com), a revised, reconstructed version of MIT's Technology Review. Although it does publish speculation, most of the articles are concerned with developing technologies and potential applications. Along with descriptions of emerging technologies, the magazine describes succinctly both interesting new research and applications that may be supported by emerging technologies. Recently, there was an article on flexible solar cells in addition to a short graphic spread on artificial retinas.

But I must confess, my most engrossing reading is provided by Invention and Technology (http:// www.inventionandtechnology.com), a magazine that celebrates past and current technology. Originally this magazine was sponsored by General Motors in conjunction with American Heritage; the magazine is now connected with the Inventor's Hall of Fame, based in Akron, Ohio. (Akron is my hometown, but I haven't had a chance to visit the Hall of Fame yet). The reason I find $I \& T$ so entertaining is that it describes how devices were invented, how some technologies came into being, and the inventors behind these advances. There is usually a piece or two on old technologies that have survived into the present day, such as articles describing how docking in space was perfected and the development of the video games of the past, pinball machines. I was fascinated by a recent article on the design and construction of the first hand-held calculator, the TI-2500.

In effect, these magazines provide me with a look into the technology of the past, a survey of the current tech nology, and a glimpse into potential technologies of the future. 